\title{
Mathematical Modeling and Experimental Study of Inverse Heat Conduction Problems of Heavy Plate Laminar Cooling Process
}

\author{
Wen-hong LIU ${ }^{1, *}$, Jun-lin WANG ${ }^{2}$ and Jian YANG ${ }^{2}$ \\ ${ }^{1}$ State Key Laboratory of Synthetical Automation of Process Industries, Northeastern \\ University, Shenyang, China (liuwenhong@ise.neu.edu.cn) \\ ${ }^{2}$ College of Information Science and Engineering, Northeastern University, Shenyang, \\ China
}

Keywords: Laminar cooling, Inverse heat conduction problem, Conjugate gradient method, Genetic algorithm, Non-iterative method.

\begin{abstract}
The performance of hot rolling steel plates depends on the cooling process after hot rolling. One important point of improving the technology of controlled cooling after rolling is understanding the effect of process parameters. Heat transfer coefficient is a significant physical parameter during the cooling process. In this paper, a mathematical model of inverse heat conduction problem was built and the laminar cooling process was studied by experiment. The main works included data acquisition, inverse heat conduction problem model and verification of algorithms. The research results show that the rate of cooling is proportional to the cooling water flow, and the effect of cooling water flow to the measure point that near the periphery is greater than the point inside. The Conjugate Gradient Method and the Genetic Algorithm are appropriate for the nolinear inverse heat conduction problem, which is proved by examples. And the computational accuracy used the measure point that near the periphery is higher than the point inside.
\end{abstract}

\section{Introduction}

Laminar cooling process is the last process before the finished hot rolling production. This process is very important and it directly decides the quality of the final products. The key of quality improvement is to develop a cooling strategy through accurate calculation with the laminar cooling process model [1] [2]. One of the major physical property parameters that decide the precision of the model is the water cooling heat transfer coefficient. However, the traditional way of calculating the coefficient which is dependent on empirical formula cannot ensure the precision [3] [4]. Therefore, an experimental study like this is needed. Fig.1 shows some equipment diagram of the laminar cooling area.

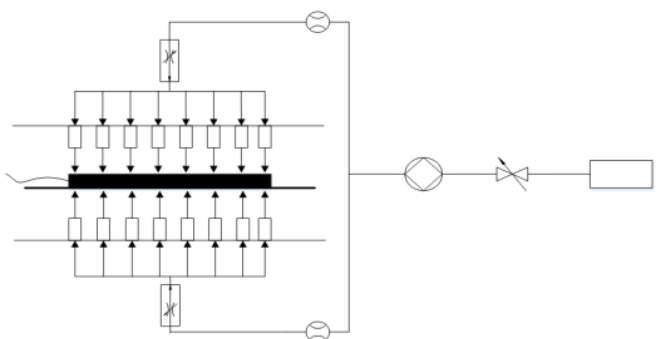

Figure 1. Equipment diagram of laminar cooling area 
In this paper, the mathematical model of inverse heat conduction problem is set up and the laminar cooling process is studied by experiment [5] [6]. The temperature data of three measure points during the laminar cooling process is acquired by thermocouples and the temperature acquisition device. The effects of cooling water flow are considered. The two-dimensional transient heat transfer model is built by finite difference method based on the heavy plate laminar cooling theory. The validity of three models based on the experiment data is verified. Advantages and disadvantages of different methods in solving the inverse heat conduction problem are analyzed. The effects of measuring point position are considered. Fig.2 shows the experiment equipment.
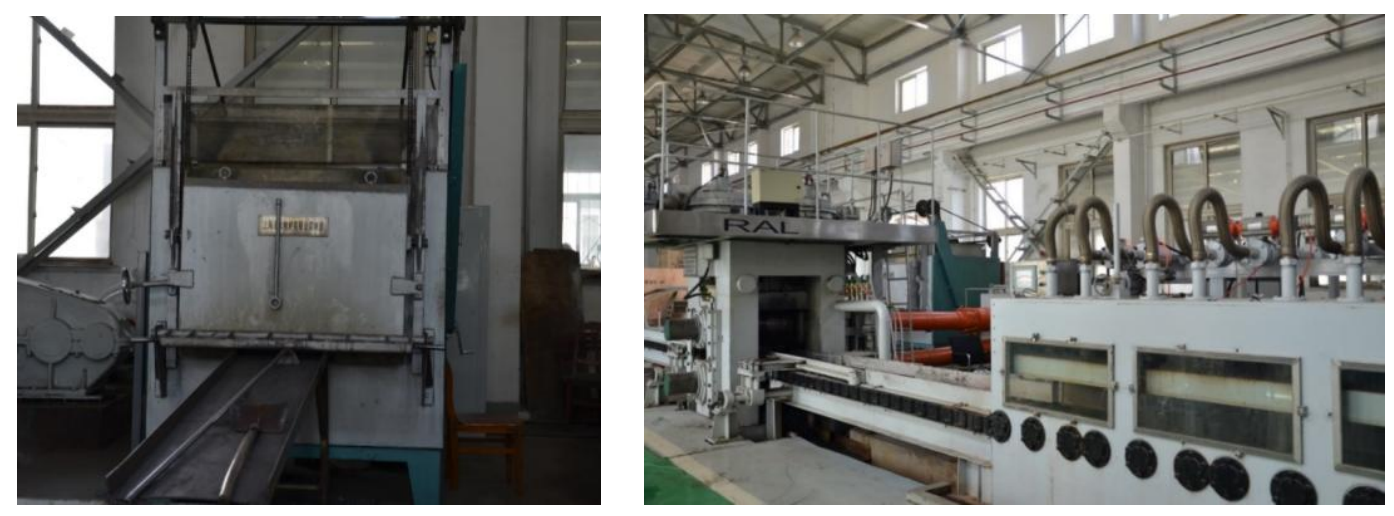

Figure 2. The experiment equipment

\section{Data Acquisition Experiment}

The multi-channel temperature data collection system is built on ADAM-4018 temperature data acquisition modules. This dissertation uses ADAM-4018 temperature data acquisition modules to transfer the real-time analog data into digital data and transmit it to upper computer through RS-232/RS-485 serial port. During the cooling process, the upper computer uses VB 6.0 to display, store, real-time monitor and it acquire the temperature data of the internal points which are $7.5 \mathrm{~mm}, 15 \mathrm{~mm}$ and $22.5 \mathrm{~mm}$ from the upper surface of the steel plate. Fig. 3 shows the test specimen and the drilling program. There are three holes in different deeps.
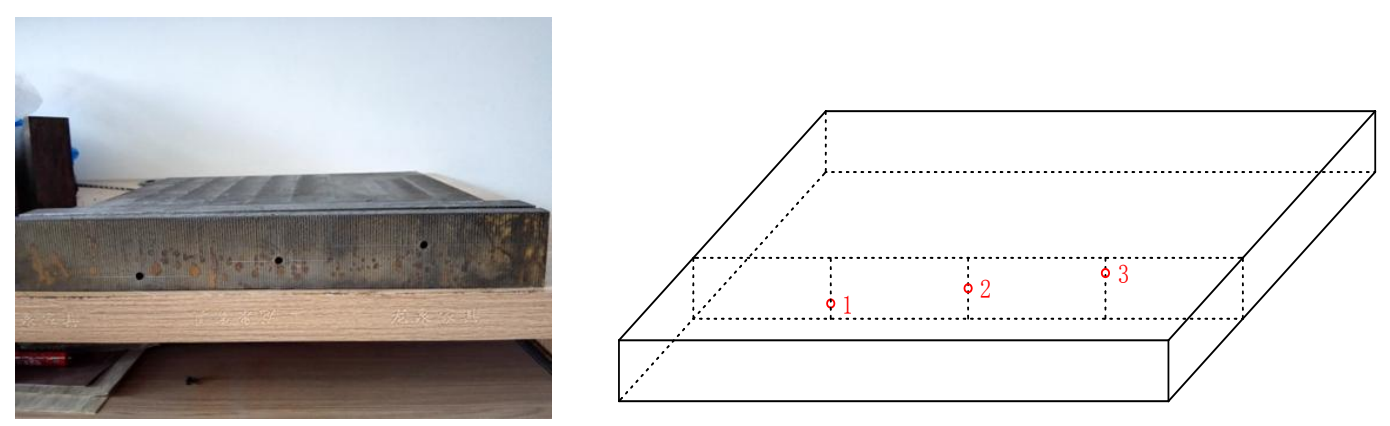

Figure 3. Test specimen and drilling program

Simulation study on the processes of the experiment. Using COMSOL software to develop a heat transfer model, this dissertation analyzes the influences of punching on the temperature field of the steel plate sample based on the punch location, aperture and other 
relevant factors. Based on the analysis, it is decided to punch holes on the side of the steel plates to place thermocouples. The thermocouples that measures temperature in this experiment are k-type thermocouples (nickel-chromium/nickel-silicon). Fig.4 shows the temperature difference curves of the three points calculated by COMSOL software. The maximum temperature difference is less than $4{ }^{\circ} \mathrm{C}$ and it is allowable for the experiment.

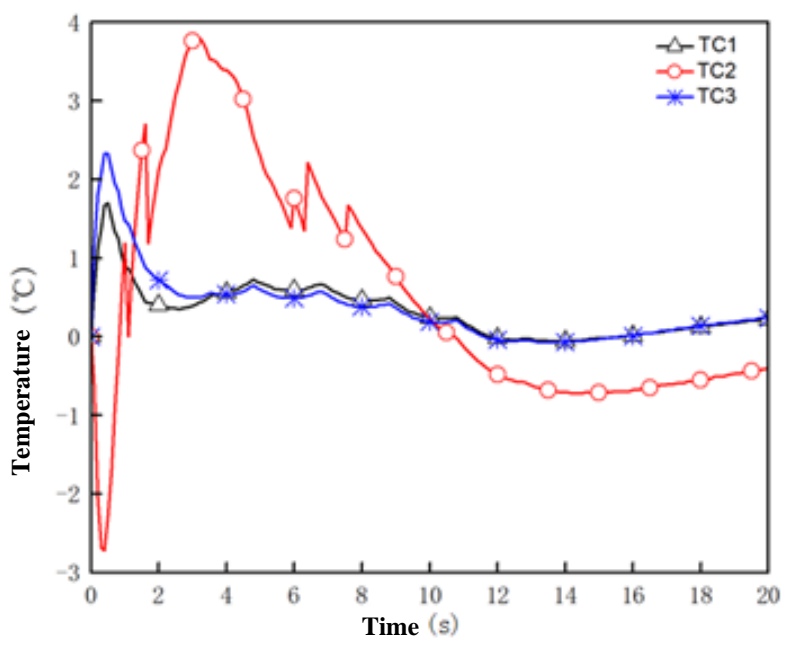

Figure 4. Test specimen and drilling program

The experiment water flowrate is $2.35 \mathrm{~m}^{3} / \mathrm{h}$ and $0.95 \mathrm{~m}^{3} / \mathrm{h}$ in test 1 and test 2 . Fig.5 shows the temperature curves for two tests.

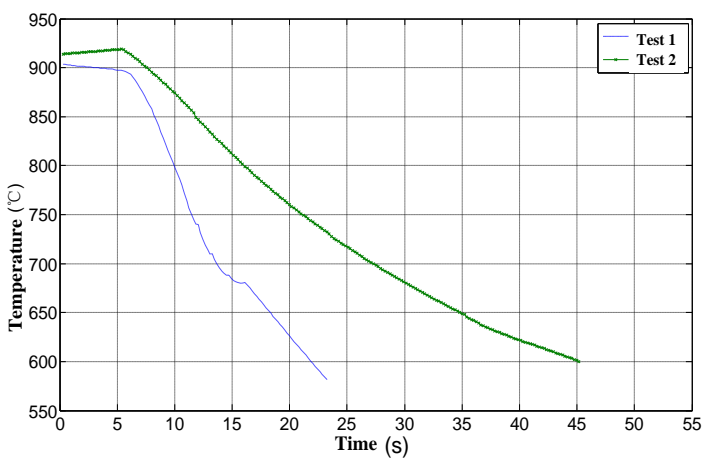

(a) Point 1 temperature curves for two tests

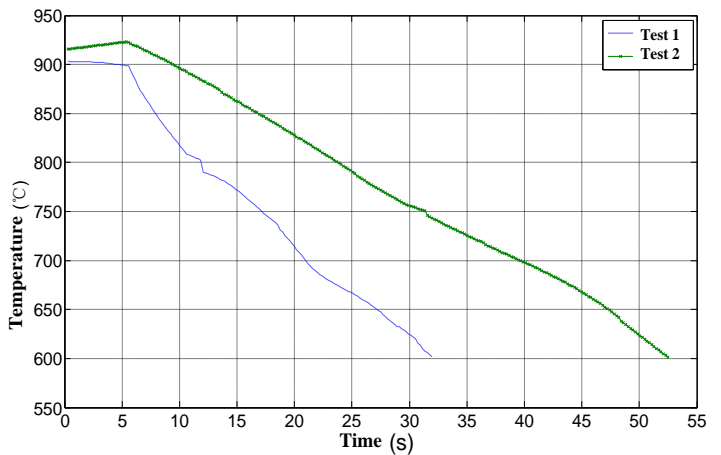

(b) Point 2 temperature curves for two tests

Figure 5. Temperature curves for two tests

\section{Inverse Heat Conduction Problem Model}

The two-dimensional transient heat transfer model is built by finite difference method based on the heavy plate laminar cooling theory. The model of inverse heat conduction problem used Conjugate Gradient Method, Genetic Algorithm and Non-iterative Method are built in MATLAB language.

The basic idea of Conjugate Gradient Method is to construct a set of conjugate directions by the gradient at known points, search along the directions and obtain the minimum point of the objective function. The objective function is as the following: 


$$
J(R)=\sum_{i=1}^{M}\left[T_{i}^{c}-T_{i}^{m}\right]^{2}
$$

where $\mathrm{R}$ is amount to be retrieved, $\mathrm{M}$ is set number of test points, $T_{i}^{c}$ is the calculated temperature of the test point $\mathrm{i}\left({ }^{\circ} \mathrm{C}\right), T_{i}^{m}$ is the measured temperature of the test point $\mathrm{i}\left({ }^{\circ} \mathrm{C}\right)$.

The basic idea of genetic algorithm is to select the initial population, crossover, mutation and other operations, and select the optimal solution of the problem. Roulette selection method is adopted as the selection operator by taking the crossover operator 0.9 , and the mutation operator 0.1 . The fitness function is as the following:

$$
F=1000-\sqrt{\frac{1}{M} \sum_{i=1}^{M}\left(T_{i}^{m}-T_{i}^{c}\right)^{2}}
$$

Non-iterative Method is that based on the matrix equations of heat conduction problem, the matrix equations of the inverse problem are obtained by the linear transformation of the unknown quantity of the new boundary conditions introduced, and the parameters to be computed are got by solving the matrix equations of the inverse problem. The finite element method is used to solve the heat conduction problem. The eventual matrix equations are as the following:

$$
[K]\{T\}_{t}+[N]\left\{\frac{\partial T}{\partial t}\right\}_{t}=\{P\}_{t}
$$

where $[\mathrm{K}]$ is temperature stiffness matrix, $[\mathrm{N}]$ is unsteady temperature matrix, $\{\mathrm{T}\}$ is column vector of unknown temperature value, $\{\mathrm{P}\}$ is column vector consisting of right end items.

By introducing the unknown quantity of the new boundary conditions, the matrix equations of the inverse problem are solved. The eventual matrix equations are as the following:

$$
\left(\left[K^{\prime}\right]+\frac{\left[N^{\prime}\right]}{\Delta t}\right)\{T q\}_{t}=\left\{p^{\prime}\right\}_{t}+\frac{[N]}{\Delta t}\{T\}_{t-\Delta t}
$$

where $\{T q\}_{t}$ is unknown vector.

\section{Verification of Algorithms and Conclusions}

The validity of three models based on the experiment data is verified. Advantages and disadvantages of different methods in solving the inverse heat conduction problem are analyzed. The effects of measuring point position are considered. In the experiment, we find that the positions for measuring the temperature are required for the Non-iterative Method, and so further research is needed for the third method. Tab. 1 and Tab. 2 show the measured temperature and the calculated temperature by the first two methods. 
Table 1. Measured temperature and calculated temperature of point 2 by Conjugate Gradient Method

\begin{tabular}{|c|c|c|c|}
\hline Time $(\mathrm{s})$ & $\begin{array}{c}\text { Measured } \\
\text { temperature }\left({ }^{\circ} \mathrm{C}\right)\end{array}$ & $\begin{array}{c}\text { Calculated } \\
\text { temperature }\left({ }^{\circ} \mathrm{C}\right)\end{array}$ & Error $\left({ }^{\circ} \mathrm{C}\right)$ \\
\hline 10 & 895.9 & 889.9980 & 5.9020 \\
\hline 15 & 863 & 853.9642 & 9.0358 \\
\hline
\end{tabular}

Table 2. Measured temperature and calculated temperature of point 2 by Genetic Algorithm

\begin{tabular}{|c|c|c|c|}
\hline Time $(\mathrm{s})$ & $\begin{array}{c}\text { Measured } \\
\text { temperature }\left({ }^{\circ} \mathrm{C}\right)\end{array}$ & $\begin{array}{c}\text { Calculated } \\
\text { temperature }\left({ }^{\circ} \mathrm{C}\right)\end{array}$ & Error $\left({ }^{\circ} \mathrm{C}\right)$ \\
\hline 10 & 895.9 & 889.1285 & 6.7715 \\
\hline 15 & 863 & 853.4819 & 9.5181 \\
\hline
\end{tabular}

The results show that the rate of cooling is proportional to the cooling water flow, and the effect of cooling water flow to the measure point that near the periphery is greater than the point inside. The Conjugate Gradient Method and the Genetic Algorithm are appropriate for the no-linear inverse heat conduction problem, which is proved by examples. And the computational accuracy used the measure point that near the periphery is higher than the point inside.

\section{Acknowledgment}

The authors would like to thank Mr. D.H. ZHANG and Mrs. H.J. MENG for their valuable suggestions and field measure assistance. This project is supported by National Natural Science Foundation of China (61333006 and 61273178).

\section{References}

[1] H. B. Xie, X. H. Liu, G. D. Wang, Optimization and model of laminar cooling control system for hot strip mills, Journal of Iron and Steel Research (International). 13 (2006) 18-22.

[2] D. Auzinger, Recent development in process optimization for laminar cooling in hot strip mills, Ironmaking and Steelmaking. 23 (1996) 84-87.

[3] D. Y. Gong, J. Z. Xu, L. G. Peng, Self-learning and its application to laminar cooling model of hot rolled strip, Journal of Iron and Steel Research (International). 14 (2007) 11-15.

[4] K. Z. Omata, H. S. Yoshimura, S. H. Yamamoto, Leading High Performance Steel Plates with Advanced Manufacturing Technologies, NKK Technical Review. (2003) 73-80.

[5] M. Samai, T. Loulou, A comparative Study of Heat Flux and Temperature Based Objective Functional to Solve Inverse Heat Conduction Problems, Numerical Heat Transfer. 56 (2009) 75-104.

[6] K. Hamed, K. Farshad, Solution of inverse heat conduction problem using the lattice Boltzmann method, International Journal of Heat and Mass Transfer. 39 (2012) 1410-1415. 